\title{
Erratum to: Current and Novel Aspects on the Non-lysosomal $\beta$-Glucosylceramidase GBA2
}

\author{
Massimo Aureli ${ }^{1} \cdot$ Maura Samarani $^{1} \cdot$ Nicoletta Loberto $^{1} \cdot$ Giulia Mancini $^{1}$. \\ Valentina Murdica $^{1}$ - Elena Chiricozzi ${ }^{1} \cdot$ Alessandro Prinetti $^{1} \cdot$ Rosaria Bassi $^{1}$. \\ Sandro Sonnino ${ }^{1}$
}

Published online: 28 January 2016

(C) Springer Science+Business Media New York 2016

\section{Erratum to: Neurochem Res}

DOI 10.1007/s11064-015-1763-2

The original version of this article unfortunately contained a mistake in author group. The given name and the family name of all the authors were interchanged.

The author names are corrected as: Massimo Aureli, Maura Samarani, Nicoletta Loberto, Giulia Mancini, Valentina Murdica, Elena Chiricozzi, Alessandro Prinetti, Rosaria Bassi, Sandro Sonnino with this erratum.

Massimo Aureli and Maura Samarani have contributed equally to the work.

The online version of the original article can be found under doi:10.1007/s11064-015-1763-2.

Sandro Sonnino

sandro.sonnino@unimi.it

1 Department of Medical Biotechnology and Translational Medicine, University of Milano, Milano, Italy 